\title{
Clinical outcomes of preoperative chemoradiotherapy in octogenarian with locally advanced rectal cancer
}

\author{
TAKESHI NISHIKAWA, KAZUSHIGE KAWAI, KEISUKE HATA, SHIGENOBU EMOTO, KOJI MURONO, \\ KAZUHITO SASAKI, TOSHIAKI TANAKA, HIROAKI NOZAWA and SOICHIRO ISHIHARA
}

Department of Surgical Oncology, The University of Tokyo, Tokyo 113-8655, Japan

Received January 7, 2019; Accepted May 30, 2019

DOI: $10.3892 /$ mco.2019.1873

\begin{abstract}
The number of elderly patients who receive surgical treatment for rectal cancer has gradually increased with aging of the population. In recent years, preoperative chemoradiotherapy, followed by surgical treatment, has been widely used for treating patients with locally advanced rectal adenocarcinoma. The aim of the present study was to evaluate if preoperative chemoradiotherapy is efficacious and safe for the treatment of rectal cancer in patients older than 80 years. A total of 293 patients with rectal cancer, who received preoperative chemoradiotherapy from 2007 to 2017, were studied. Comorbidities and the short- and long-term outcomes in elderly patients (aged $\geq 80$ years old) were investigated and compared to younger patients. The elderly group comprised of 17 patients $(5.8 \%)$. Pulmonary disease was the most common comorbidity $(23.5 \%)$. No significant difference between the two groups regarding the rate of completeness of chemoradiotherapy was detected $(\mathrm{P}=0.26)$. Curative resection was performed in 14 patients in the elderly group and 252 patients in the younger group. Among 7 patients from both groups who could not receive curative resection due to their poor general condition, 4 patients had decreased lower respiratory function due to pneumonia (3 patients) or chronic obstructive pulmonary disease (1 patient). Morbidity and mortality rates were similar in elderly and younger groups ( $35.7 \%$ vs. $27.0 \%, 0 \%$ vs. $0 \%$, respectively; $\mathrm{P}=0.54, \mathrm{P}=1.00$ ). No significant difference was found regarding recurrence between the two groups $(\mathrm{P}=1.00)$. To conclude, preoperative chemoradiotherapy in elderly patients with rectal cancer is safe and well tolerated.
\end{abstract}

Correspondence to: Dr Takeshi Nishikawa, Department of Surgical Oncology, The University of Tokyo, 7-3-1 Hongo, Bunkyo-ku, Tokyo 113-8655, Japan

E-mail: takn-tky@umin.ac.jp

Abbreviations: CRT, chemoradiotherapy; RT, radiotherapy

Key words: preoperative chemoradiotherapy, elderly, rectal cancer, morbidity, pulmonary disease

\section{Introduction}

Colorectal cancer is the third most common malignancy and a leading cause of cancer-related deaths worldwide (1). Along with an aging of the population, the number of elderly patients who receive surgical treatment for colorectal cancer has gradually increased. The median age at diagnosis of colorectal cancer is 69-72 years, with $60-70 \%$ of all cases diagnosed in patients over the age of 65 (2). Approximately, 17.5\% of colorectal cancer patients are diagnosed when they are over 80 years old (1). Unfortunately, most elderly patients have comorbidities, such as cardiovascular or pulmonary diseases, and reduced functional reserve, which may increase their risks of postoperative morbidity and mortality and subsequently influence the treatment choice (e.g., avoiding curative resection).

In recent years, preoperative chemoradiotherapy (CRT) with fluorouracil-based chemotherapy and at least $45.0 \mathrm{~Gy}$ of pelvic radiation, followed by surgical treatment, has been widely used for treating patients with resectable locally advanced rectal adenocarcinoma, because this approach facilitates tumor downstaging, increases sphincter preservation, and decreases locoregional recurrence (3-5). Most studies have used cutoff ages of 60 or 70 years old; therefore, few studies with elderly patients over 80 years, which occupy one sixth of colorectal cancer patients, have been published. The safety and effectiveness of preoperative CRT in octogenarians with locally advanced rectal cancer has not been determined.

The purpose of this study was to evaluate if preoperative CRT is efficacious and safe for the treatment of locally advanced rectal cancer in patients older than 80 years.

\section{Materials and methods}

Patients and methods. From 2007 to 2017, a total of 293 patients with histologically confirmed non-metastatic, primary adenocarcinoma of the lower rectum below the peritoneal reflection invading further than the muscularis propria (cT3-T4, any N), who received preoperative CRT, were studied retrospectively at the University of Tokyo Hospital. All patients, except those with obstruction, received a total colonoscopy with a biopsy. All patients were preoperatively evaluated with thoracic and abdominal computed tomography, pelvic magnetic resonance imaging (MRI) and positron emission tomography, if needed. Patients who received prior chemotherapy for rectal cancer or 
any prior pelvic irradiation, patients with inflammatory bowel disease, patients with a history of malignant disease within five years of diagnosis with rectal cancer and patients who received palliative CRT were excluded from this study. The study was conducted in accordance with the ethical guidelines of the Declaration of Helsinki and approved by the Ethics Committee of the University of Tokyo [no.3252-(7)].

Preoperative CRT. Radiotherapy (RT) was administered five times per week with a daily fraction of $1.8 \mathrm{~Gy}$. A total dose of 50.4 Gy was delivered with photons using a 10 MV X-ray accelerator in 28 fractions over the course of 5.6 weeks, using a 3- or 4-field technique. Preoperative chemotherapy was started simultaneously with RT. Patients received 5-fluorouracil-based chemotherapy. Surgery, including total mesorectal excision or tumor-specific mesorectal excision techniques, was performed 6 to 8 weeks after the completion of CRT. Lateral pelvic lymph node dissection was selectively performed in cases suspected of lateral pelvic lymph node metastasis in the preoperative MRI before CRT regardless of its response to CRT. In this study, lymph nodes with diameter of $8 \mathrm{~mm}$ or larger in MRI were considered as suspect of metastasis. No short-course RT was performed in the study period.

Study assessments. We investigated comorbidities, short-term outcomes (i.e., adverse events during CRT, curative resection rate, pathological complete response (pCR), morbidity, and mortality), and long-term outcomes (i.e., recurrence rate and site) in elderly ( $\geq 80$ years old) and younger patients ( $<80$ years old) and compared the two groups. Robotic surgery was considered as a laparoscopic technique and included in laparoscopic surgery. Curative resection was defined as the macroscopically complete removal of the tumor and lymph nodes with a microscopically tumor-free resection margin and no peritoneal spread or distant metastasis. In laparoscopic surgery, the resected specimen was retrieved from a small incision at the umbilicus port site, which was made according to the tumor size, or from the perineal incision. Conversion of laparoscopic surgery to open surgery was defined as an abdominal incision different from that planned at the start of the operation. The results of examination were classified according to the TNM classification of The International Union Against Cancer (UICC) (6). Adverse events were evaluated using the National Cancer Institute's Common Terminology Criteria for Adverse Events, version 4.0 (7). The tumor regression grade was determined according to the general rules for clinical and pathological studies on cancer of the colon, rectum, and anus of the Japanese Society for Cancer of the Colon and Rectum (8). pCR (grade 3) was defined as the absence of viable cancer cells in the primary tumor and lymph nodes. Other grades were defined as: i) grade 1a, less than one third of the cancer had degraded, necrotized, or disappeared; ii) grade $1 b$, from one third to two thirds of the cancer had degraded; and iii) grade 2, more than two thirds of the cancer had degraded. Patients were discharged when they had sufficient oral intake, no complications or well-controlled complications, and no excessive anxiety about leaving the hospital. Short-term morbidity and mortality was defined as 30-day or in-hospital morbidity and mortality according to the Clavien-Dindo classification. As follow-up, a blood test was performed every three months after the surgery, and computed tomography of the pelvis combined with imaging of the liver and the chest was performed every six months after the surgery. Recurrence was defined as the presence of locoregional recurrence, the presence of distant metastases, or death from colorectal cancer.

Statistical analysis. For categorical variables, data were presented as frequencies and percentage, and Fisher's exact probability test was applied to evaluate the significance of differences in proportions. Continuous variables such as 'Days hospitalized after surgery' shown as median were estimated using the Mann-Whitney U test. Differences in survival between groups were assessed using the log-rank test. Associations were considered significant when $\mathrm{P}<0.05$.

\section{Results}

From 2007 to 2017, a total of 293 patients with locally advanced rectal cancer received preoperative CRT. The distribution of age groups is shown in Fig. 1. The percentage of patients was highest in the 60-69-year-old age group (5.8\%). In the group comprised of octogenarians (elderly group) were 17 patients, and the younger group had 276 patients. The oldest patient was 88 years old. In elderly group, four patients did not receive preoperative CRT during the study period.

Patient characteristics and chemotherapy regimens are shown in Table I. The percentage of males in elderly and younger groups was 29 and $67 \%$, respectively $(\mathrm{P}=0.003)$. There was no statistical difference between the two groups regarding comorbidities. Nearly $60 \%$ of the patients in the elderly group presented with comorbidities; pulmonary comorbidity was the most common one in that group (23.5\%). We found a statistically significant difference between elderly and younger groups in preoperative therapy. Elderly patients were more likely to receive $\mathrm{RT}$ due to their age $(\mathrm{P}=0.0008)$. In the younger group, only five patients $(1.8 \%)$ received RT because of patient selection, renal dysfunction, or liver dysfunction in two, two, and one patient, respectively. The following regimens were employed as chemotherapy: Oral tegafur-uracil and leucovorin $(n=245)$, oral S-1 $(n=10)$, oral tegafur-uracil and leucovorin with intravenous irinotecan $(n=24)$ and oral S-1 with intravenous oxaliplatin $(n=5)(9)$. There was no statistical difference between the two groups regarding the distance of the tumor from the anal verge and clinical stage.

Adverse events during CRT are shown in Table II. There was no statistical difference between the two groups related to the rate of completeness of CRT $(\mathrm{P}=0.26)$. Adverse events occurred in $88.2 \%$ of the elderly group including grade 1-3, but there was no significant difference between the two groups $(\mathrm{P}=0.17)$. Diarrhea was the most common side effect in the elderly group (seven cases). Pneumonia occurred in three patients in this study. Grade 3 adverse events occurred in three patients of the elderly group (diarrhea in two, pneumonia in one) and in five patients of the younger group (diarrhea in three, radiation dermatitis in one, proctitis in one). No death during preoperative CRT occurred in either group.

The surgical procedures performed are shown in Table III. Curative resection was performed in fourteen patients $(82.4 \%)$ in the elderly group and no treatment was performed in the remaining three patients because of poor general condition. On the other hand, curative resection was performed in $91.3 \%$ of 
Table I. Patient characteristics.

\begin{tabular}{|c|c|c|c|}
\hline Variable & Elderly group (n=17) & Younger group $(n=276)$ & P-value \\
\hline Sex & & & 0.003 \\
\hline Male & 5 & 185 & \\
\hline Female & 12 & 91 & \\
\hline \multicolumn{4}{|l|}{ Treatment before CRT } \\
\hline Colostomy/Ileostomy & 0 & 8 & 1.0 \\
\hline \multicolumn{4}{|l|}{ Comorbidities } \\
\hline Overall (\%) & $10(58.8 \%)$ & $127(46.0 \%)$ & 0.33 \\
\hline Cardiovascular & $1(5.9)$ & $25(9.1)$ & 1.0 \\
\hline Hypertension & $3(17.6)$ & $71(25.7)$ & 0.57 \\
\hline Pulmonary & $4(23.5)$ & $43(15.6)$ & 0.49 \\
\hline Liver & $2(11.8)$ & $10(3.6)$ & 0.15 \\
\hline Renal & $1(5.9)$ & $9(3.3)$ & 0.44 \\
\hline Cerebrovascular & $3(17.6)$ & $16(5.8)$ & 0.09 \\
\hline Diabetes mellitus & $1(5.9)$ & $36(13.0)$ & 0.71 \\
\hline Preoperative therapy & & & 0.0008 \\
\hline CRT & 13 & 271 & \\
\hline RT & 4 & 5 & \\
\hline Tegafur-uracil/leucovorin & 13 & 232 & \\
\hline S-1 & & 10 & \\
\hline CPT-11 + tegafur-uracil/leucovorin & & 24 & \\
\hline Oxaliplatin + S-1 & & 5 & \\
\hline The distance of the tumor from the anal verge & & & 0.13 \\
\hline$\leq 4 \mathrm{~cm}$ & 12 & 145 & \\
\hline $4.1-8 \mathrm{~cm}$ & 5 & 119 & \\
\hline $8.1-10 \mathrm{~cm}$ & & 12 & \\
\hline Clinical stage & & & 0.27 \\
\hline $2 \mathrm{a}$ & 10 & 138 & \\
\hline $2 b$ & & 2 & \\
\hline $2 \mathrm{c}$ & 2 & 1 & \\
\hline $3 b$ & 3 & 92 & \\
\hline $3 c$ & 2 & 9 & \\
\hline 4 & & 34 & \\
\hline
\end{tabular}

the patients in the younger group and non-curative treatment or no treatment was performed in twenty-four patients, because of refusal of resection by seven patients, and poor general condition in four patients, and various reasons in the remaining 13 patients. The curative resection rate was similar between the two groups $(\mathrm{P}=0.20)$. The general condition after CRT was worse in the elderly group than in the younger group; the rate of poor general condition in elderly group was significantly higher than that in younger patients $(\mathrm{P}=0.005)$. In total seven patients from both groups could not receive curative resection due to poor general condition during or after CRT, four patients (three in the younger and one in the elderly group) had decreased lower respiratory function due to pneumonia in three patients and Chronic obstructive pulmonary disease (COPD) in one, and one patient each suffered from severe appetite loss or fatigue. Laparoscopic surgery was a preferred procedure in the elderly group $(\mathrm{P}=0.052)$. No conversion to open surgery was required in either group. Lateral lymph node dissection was performed in 39 patients in the younger group, but in none of the patients in the elderly group $(\mathrm{P}=0.23)$. The rate of diverting stoma construction was similar in both groups $(\mathrm{P}=0.39)$. The closure ratio of diverting stoma was not statistically different between elderly and younger groups (66.7\% vs. $62.0 \%, \mathrm{P}=0.55)$.

Postoperative course is shown in Table IV. We observed pCR in one patient (7.1\%) in the elderly group and in 27 patients $(10.7 \%)$ in the younger group $(\mathrm{P}=0.20)$. There was no statistical difference between the two groups regarding pathological stage. The morbidity rate, higher than Clavien-Dindo classification grade 2, was similar in elderly and younger groups $(35.7 \%$ vs. $27.0 \%$, respectively, $\mathrm{P}=0.54)$; the mortality rate after surgery was zero in both groups. Patients in the elderly group were associated with a longer hospital stay compared to the younger group (23.5 days vs. 19 days, respectively, $\mathrm{P}=0.07$ ), because patients were discharged when they had no excessive anxiety about leaving the hospital. Adjuvant chemotherapy was given to three patients in the elderly group. Two patients received tegafur-uracil/leucovorin and one 


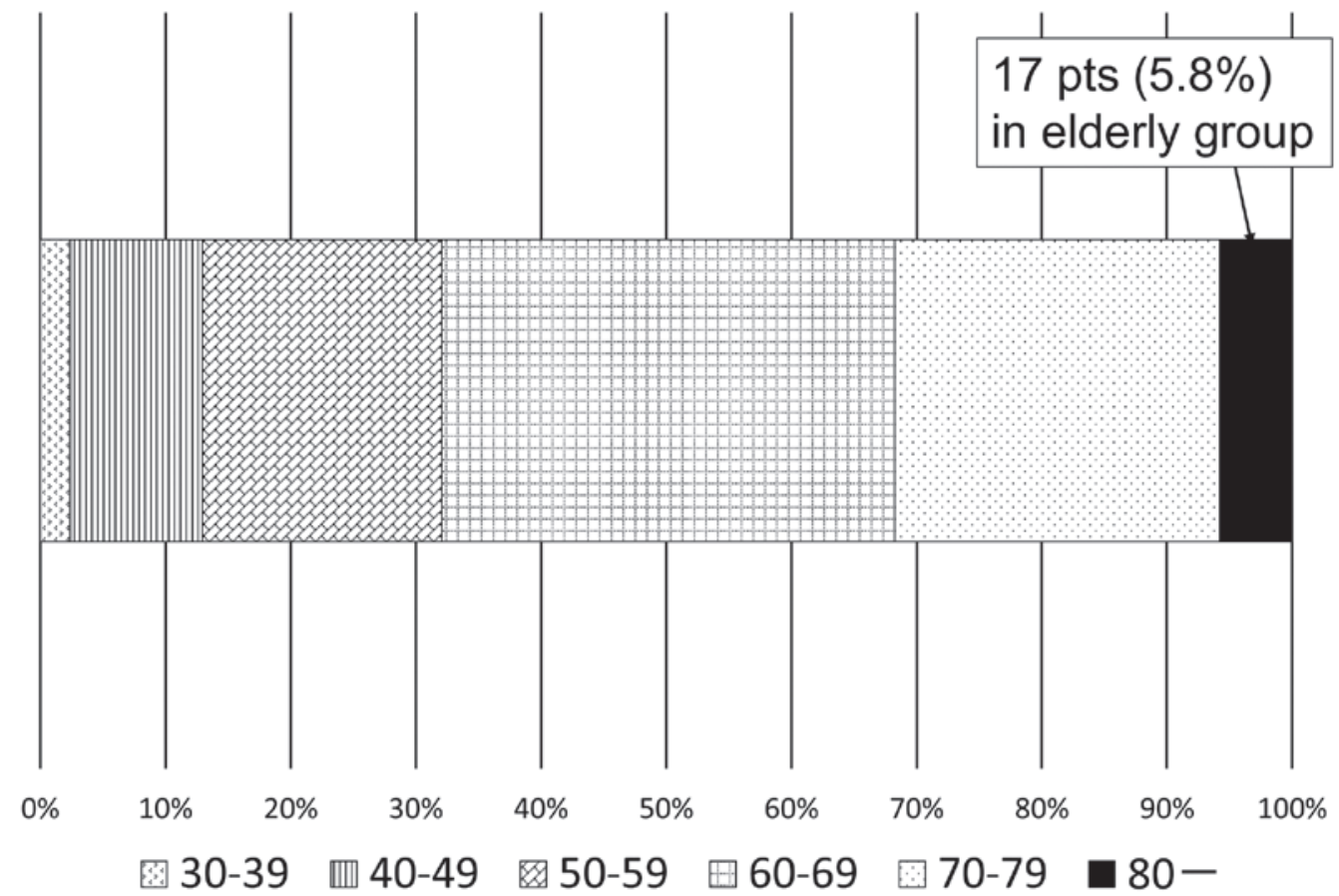

Figure 1. Number of patients with rectal cancer treated with chemoradiotherapy by age group ( $\mathrm{n}=293)$. In the octogenarian (elderly) group were 17 patients (5.8\%).

Table II. Adverse events during CRT.

\begin{tabular}{lccc}
\hline Variable & $\begin{array}{c}\text { Elderly } \\
\text { group } \\
(\mathrm{n}=17)\end{array}$ & $\begin{array}{c}\text { Younger } \\
\text { group } \\
(\mathrm{n}=276)\end{array}$ & P-value \\
\hline Result of CRT & & & 0.26 \\
$\quad$ Complete & $15(88.2 \%)$ & $261(94.6 \%)$ & \\
Dose reduction & 1 & 13 & \\
Cessation & 1 & 2 & \\
Adverse event & & & \\
Overall & $15(88.2 \%)$ & $197(71.4 \%)$ & 0.17 \\
Diarrhea & 7 & 67 & 0.15 \\
Anal pain & 5 & 114 & 0.45 \\
Radiation dermatitis & 1 & 27 & 1.0 \\
Cystitis & 1 & 6 & 0.34 \\
Pneumonia & 1 & 2 & 0.16 \\
Proctitis & & 5 & 1.0 \\
Gonitis & & 1 & 1.0 \\
Backache & & 1 & 1.0 \\
Neutropenia & & 5 & 1.0 \\
Melena & & 2 & 1.0 \\
Anorexia & 1 & 1 & 0.11 \\
Nausea & & 3 & 1.0 \\
Fatigue & 1 & & 0.06 \\
Appetite loss & 1 & 1 & 0.11 \\
Death & 0 & 0 & 1.0 \\
\hline
\end{tabular}

received capecitabine. Although a smaller percentage of elderly patients received adjuvant chemotherapy, there was no significant difference between elderly and younger groups ( $21.4 \%$ vs.
$37.3 \%, \mathrm{P}=0.12)$. No significant difference was found in the recurrence rate between the two groups $(\mathrm{P}=1.00)$. Three patients in the elderly group, and 60 patients in the younger group developed recurrences including lymph node metastases outside the pelvis. Among the 3 cases of the elderly group, one recurred with lung metastasis and lymph node metastasis outside the pelvis, one had lung metastasis, and one had lymph node metastasis outside the pelvis. Among the 60 cases of the younger group, 10 recurred with lymph node metastases, and 7 of them were outside the pelvis.

\section{Discussion}

In a previous German randomized study, $92 \%$ of patients aged $\leq 76$ years received the prescribed RT and $89 \%$ completed preoperative CRT (10). In our study, $88.2 \%$ of elderly patients received the complete dose of preoperative CRT, which is comparable to that from the previous study. A recent American retrospective study showed that $5 \%$ of patients aged $\leq 68$ years received incomplete doses of radiation in neoadjuvant CRT (3). In that study, Freischlag et al (3) also revealed that female patients, patients who received preoperative therapy and surgery at different facilities, and patients without insurance were less likely to complete preoperative therap. In our study, all patients had national health insurance and received preoperative CRT and surgery at the same hospital. Although there was a larger percentage of female patients in the elderly rectal cancer group, the complete rate of preoperative CRT was not significantly different between the two groups.

In our study, octogenarians were more likely to receive RT due to their age ( $\mathrm{P}=0.0008)$. Cai et al (11) revealed that grade 3 toxicities (diarrhea, skin toxicity, and neutropenia) occurred more often in elderly rectal cancer patients ( $\geq 70$ years old) treated with CRT compared to those treated 
Table III. Surgical procedure.

\begin{tabular}{|c|c|c|c|}
\hline & Elderly group $(\mathrm{n}=17)$ & Younger group $(n=276)$ & P-value \\
\hline Curative resection & $14(82.4 \%)$ & $252(91.3 \%)$ & 0.2 \\
\hline Worse general condition & 3 & 4 & 0.0049 \\
\hline Approach & & & 0.051 \\
\hline Laparoscopic surgery (robot) & $12(3)$ & $148(37)$ & \\
\hline Open surgery & 2 & 104 & \\
\hline Conversion to open surgery & $0(0 \%)$ & $0(0 \%)$ & \\
\hline Types of operation & & & 0.046 \\
\hline Low anterior resection & 5 & 149 & \\
\hline Intersphincter resection & 1 & 42 & \\
\hline Hartmann's operation & 2 & 3 & \\
\hline Abdominoperineal resection & 6 & 56 & \\
\hline Total pelvic exenteration & 2 & & \\
\hline Lateral lymph node dissection & 0 & 39 & 0.23 \\
\hline \multicolumn{4}{|l|}{ Diverting stoma } \\
\hline Construction & $3(21.4 \%)$ & $92(36.5 \%)$ & 0.39 \\
\hline Closure & $2(66.7 \%)$ & $57(62.0 \%)$ & 0.55 \\
\hline
\end{tabular}

with RT. Guimas et al (12), noted an increase in morbidity with the addition of oxaliplatin to standard CRT, and Margalit et al (13), demonstrated that treatment intensification should be performed with care in elderly rectal cancer patients ( $\geq 70$ years old) treated with preoperative CRT or RT, because the majority of elderly patients required early termination of treatment, treatment interruptions, or dose reductions. On the other hand, several studies showed that neoadjuvant CRT in elderly rectal cancer patients was a well-tolerated treatment without any significant increase in acute and late toxicities (14-17). In the present study, there was no statistical difference between elderly and younger groups related to the result of neither CRT nor the adverse event during CRT. Therefore, although the majority of elderly patients could safely undergo preoperative treatment consisting of RT combined with oral tegafur-uracil and leucovorin, we need to carefully select the elderly rectal cancer patients when adding oxaliplatin or irinotecan to standard CRT.

Pneumonia was one of the risk factors that precluded safe performance of treatment (preoperative CRT or curative surgical procedure after CRT) in our study. Inoue et al (18), reported comparably high rates of postoperative complications in patients with pulmonary comorbidities. Furthermore, Baré et al (19), demonstrated that COPD was associated with higher rates of postoperative complications, antibiotic treatment, and mortality during hospitalization, and that patients with underlying COPD had a higher rate of postoperative infectious complications, such as septic shock, pneumonia, and other respiratory tract infections, compared to those without COPD. In a previous study, we reported two elderly patients aged $\geq 80$ years with colorectal cancer who underwent curative surgical resection died in the postoperative period due to pneumonia (20). Thus, to reduce pulmonary morbidity and mortality in elderly rectal cancer patients with comorbidities, intensive perioperative chest physiotherapy should be recommended. Further study is needed to implement the ideal prevention strategy for postoperative respiratory complications in elderly patients with locally advanced rectal cancer and comorbidities.

Previously, we demonstrated that laparoscopic surgery in elderly patients (octogenarians) with colorectal cancer is a safe and less invasive alternative to open surgery, with less blood loss and a shorter hospital stay (20). Several other studies also reported the safety and feasibility of laparoscopic surgery in elderly patients with colorectal cancer (21-23). However, the safety and effectiveness of laparoscopic surgery is not clear in both octogenarians and younger patients with rectal cancer treated with preoperative CRT (24-28). Further study is needed to confirm the safety and effectiveness of laparoscopic surgery for the treatment of locally advanced rectal cancer in elderly patients.

The rates of diverting stoma construction and closure were similar in elderly and younger groups in this study. According to large scale studies, 12-40\% of defunctioning stomas are never reversed for many reasons, such as cancer recurrence, anastomosis site-related complications, poor general conditions, and unsatisfactory rectal functions (29). Previous studies demonstrated that neoadjuvant CRT is an independent risk factor for stoma non-reversal $(30,31)$. We also reported on the closure rate of diverting stoma and risk factor of stoma non-reversal after low anterior resection using a nomogram (32); one of the risk factors of stoma non-reversal was preoperative CRT, but not the patient's age. Kim et al (29), also did not identify older age as a risk factor for stoma non-reversal. Therefore, when planning rectal surgery involving a temporary stoma for elderly patients with rectal cancer treated by preoperative CRT, surgeons should consider the possibility that stoma non-reversal may be caused by preoperative CRT, not by patient's age. 
Table IV. Postoperative course.

\begin{tabular}{|c|c|c|c|}
\hline & Elderly group $(n=14)$ & Younger group $(\mathrm{n}=252)$ & P-value \\
\hline Pathological complete response (pCR) & $1(7.1 \%)$ & $27(10.7 \%)$ & 0.2 \\
\hline Pathological stage & & & 0.8 \\
\hline 0 & 2 & 27 & \\
\hline 1 & 3 & 61 & \\
\hline $2 \mathrm{a}$ & 4 & 71 & \\
\hline $2 b$ & & 2 & \\
\hline $2 \mathrm{c}$ & 1 & 3 & \\
\hline $3 \mathrm{a}$ & & 13 & \\
\hline $3 b$ & 2 & 38 & \\
\hline $3 c$ & 1 & 5 & \\
\hline 4 & 1 & 32 & \\
\hline Morbidity overall & $5(35.7 \%)$ & $68(27.0 \%)$ & 0.54 \\
\hline Wound infection & 2 & 11 & 0.14 \\
\hline Intra-abdominal abscess & 1 & 10 & 0.45 \\
\hline Anastomotic leakage & & 2 & 1.0 \\
\hline Infection via catheter & & 9 & 1.0 \\
\hline Urinary tract infection & & 2 & 1.0 \\
\hline Pneumonia & & 1 & 1.0 \\
\hline Enterocolitis & & 2 & 1.0 \\
\hline Delirium & & 3 & 1.0 \\
\hline Bowel obstruction & 1 & 17 & 1.0 \\
\hline Stoma obstruction & & 3 & 1.0 \\
\hline Wound bleeding & & 1 & 1.0 \\
\hline Urinary retention & & 7 & 1.0 \\
\hline Ureter injury & & 1 & 1.0 \\
\hline Compartment syndrome & & 2 & 1.0 \\
\hline Port-site hernia & 1 & & 0.053 \\
\hline Mortality & $0(0 \%)$ & $0(0 \%)$ & 1.0 \\
\hline Days hospitalized after surgery (days) & $23.5(13-63)$ & $19(8-316)$ & 0.07 \\
\hline Median (range) & & & \\
\hline \multicolumn{4}{|l|}{ Adjuvant chemotherapy } \\
\hline Overall & $3(21.4 \%)$ & $94(37.3 \%)$ & 0.12 \\
\hline Tegafur-uracil/leucovorin & 2 & 48 & \\
\hline Capecitabine & 1 & 5 & \\
\hline S-1 & & 9 & \\
\hline XELOX & & 17 & \\
\hline SOX & & 2 & \\
\hline FOLFOX & & 13 & \\
\hline \multicolumn{4}{|l|}{ Recurrence } \\
\hline Overall & $3(21.4 \%)$ & $60(23.8 \%)$ & 1.0 \\
\hline Lung & 2 & 30 & 0.68 \\
\hline Liver & & 16 & 1.0 \\
\hline Lymph node & 2 & 10 & 0.13 \\
\hline Local & & 8 & 1.0 \\
\hline Dissemination & & 4 & 1.0 \\
\hline Brain & & 2 & 1.0 \\
\hline Skin & & 1 & 1.0 \\
\hline
\end{tabular}

In conclusion, the present study has some limitations. First, this study was not a large-scale multicenter randomized trial, but a retrospective study conducted at a single institute. Second, selection bias remains a concern. There is the possibility that some elderly patients with locally advanced rectal cancer did not receive preoperative CRT nor surgical treatment. However, beside these limitations, our current data still provide support to the concept that preoperative CRT can be performed with tolerable adverse events, completeness of CRT, and acceptable morbidity and mortality rates in elderly patients with locally advanced rectal cancer. 


\section{Acknowledgements}

Not applicable.

\section{Funding}

The present study was supported by Grants-in-Aid for Scientific Research (C: grant no. 16K07143, C: grant no. 16K07161, C: grant no. $17 \mathrm{~K} 10620, \mathrm{C}$ : grant no. 17K10621C: grant no. $17 \mathrm{~K} 10623$ and C: grant no. 18K07194) from the Japan Society for the Promotion of Science. This research was also supported by the Project for Cancer Research and Therapeutic Evolution (P-CREATE, grant no. 18cm0106502h0003) from the Japan Agency for Medical Research and Development (AMED).

\section{Availability of data and materials}

The datasets used and/or analyzed during the present study are available from the corresponding author on reasonable request.

\section{Authors' contributions}

TN was conceived the design of the manuscript and the analysis and interpretation of data and drafted the article. KK supervised the study. KH, SE, KM, KS, TT and HN participated in the design of this article and revised the paper critically for important intellectual content. SI participated in the design of this article, revised it critically for important intellectual content and gave final approval of the version to be published.

\section{Ethics approval and consent to participate}

The study was conducted in accordance with the ethical guidelines of the Declaration of Helsinki and approved by the Ethics Committee of the University of Tokyo [No. 3252-(7)].

\section{Patient consent for publication}

Patients were provided the option to opt out.

\section{Competing interests}

The authors declare that they have no competing interests.

\section{References}

1. Yang L, Ma Q, Yu YY, Wang C, Meng WJ, Adell G, Albertsson M, Arbman G, Jarlsfelt I, Peng ZH, et al: Efficacy of surgery and adjuvant therapy in older patients with colorectal cancer: A STROBE-compliant article. Medicine (Baltimore) 93: e266, 2014

2. Jacobs L, van der Vlies E, Ten Bokkel Huinink D, Bloemendal H, Intven M, Smits AB, Weusten BLAM, Siersema PD, van Lelyveld $\mathrm{N}$ and Los M: Tolerability, safety and outcome of neoadjuvant chemoradiotherapy with capecitabine in Patients Aged $\geq 70$ Years with locally advanced rectal cancer. Clin Colorectal Cancer 17: 179-186, 2018.

3. Freischlag K, Sun Z, Adam MA, Kim J, Palta M, Czito BG, Migaly J and Mantyh CR: Association between incomplete neoadjuvant radiotherapy and survival for patients with locally advanced rectal cancer. JAMA Surg 152: 558-564, 2017.

4. National Comprehensive Cancer Network: NCCN Guidelines, version 2. Rectal cancer. Fort Washington, PA: National Comprehensive Cancer Network, 2016.
5. Wong RK, Tandan V, De Silva S and Figueredo A: Pre-operative radiotherapy and curative surgery for the management of localized rectal carcinoma. Cochrane Database Syst Rev: CD002102, 2007.

6. Brierley JD, Gospodarowicz MK and Wittekind C (eds): UICC international union against cancer. TMN classification of malignant tumours. 8th edition. Wiley-Blackwell, Chichester, UK, 2017.

7. National cancer institute: Common terminology criteria for adverse events (CTCEA) version 4.0. http://www.eortic. be/services/doc/ctc/CTCAE 4.03 2010-06-14 QuickReference 5x7.pdf. Updated 20102009.

8. Japanese Society for Cancer of the Colon and Rectum: General rules for clinical and pathological studies on cancer of the colon, rectum and anus. 7th edition. Tokyo, Kanehara, 2009.

9. Matsusaka S, Ishihara S, Kondo K, Horie H, Uehara K, Oguchi M, Murofushi K, Ueno M, Mizunuma N, Shimbo T, et al: A multicenter phase II study of preoperative chemoradiotherapy with S-1 plus oxaliplatin for locally advanced rectal cancer (SHOGUN trial). Radiother Oncol 116: 209-13, 2015.

10. Sauer R, Becker H, Hohenberger W, Rödel C, Wittekind C, Fietkau R, Martus P, Tschmelitsch J, Hager E, Hess CF, et al: Preoperative versus postoperative chemoradiotherapy for rectal cancer. N Engl J Med 351: 1731-1740, 2004

11. Cai X, Wu H, Peng J, Zhu J, Cai S, Cai G and Zhang Z: Tolerability and outcomes of radiotherapy or chemoradiotherapy for rectal cancer in elderly patients aged 70 years and older. Radiat Oncol 8: 86, 2013.

12. Guimas V, Boustani J, Schipman B, Lescut N, Puyraveau M, Bosset JF and Servagi-Vernat S: Preoperative chemoradiotherapy for rectal cancer in patients aged 75 years and older: Acute toxicity, compliance with treatment, and early results. Drugs Aging 33: 419-25, 2016.

13. Margalit DN, Mamon HJ, Ancukiewicz M, Kobayashi W, Ryan DP, Blaszkowsky LS, Clark J, Willett CG and Hong TS: Tolerability of combined modality therapy for rectal cancer in elderly patients aged 75 years and older. Int J Radiat Oncol Biol Phys 81: e735-e741, 2011.

14. Tougeron D, Roullet B, Paillot B, Hamidou H, Tourani JM, Bensadoun RJ, Michel P and Silvain C: Safety and outcome of chemoradiotherapy in elderly patients with rectal cancer: Results from two French tertiary centres. Dig Liver Dis 44: 350-354, 2012.

15. Ausili Cèfaro G, Genovesi D, Vinciguerra A, Augurio A, Di Tmmaso M, Marchese R, Borzillo V, Tsciotti L, Taraborrelli M, Innocenti P, et al: Effects of preoperative radiochemotherapy with capecitabine for resectable locally advanced rectal cancer in elderly patients. Tumori 98: 622-629, 2012.

16. De Felice F, Musio D, Izzo L, Pugliese F, Izzo P, Bolognese A and Tombolini V: Preoperative chemoradiotherapy in elderly patients with locally advanced rectal cancer. Biomed Res Int 2013: 610786, 2013.

17. De Felice F, Llange K, Rubini F, Bulzonetti N, Caiazzo R, Musio D and Tombolini V: Intensified neoadjuvant chemoradiotherapy for locally advanced rectal cancer in elderly patients: Toxicity, disease control, and survival outcomes. Clin Colorectal Cancer 17: e77-e81, 2018.

18. Inoue Y, Kawamoto A, Okugawa Y, Hiro J, Saigusa S, Toiyam Y, Araki T, Tanaka K, Mohri Y and Kusunoki M: Efficacy and safety of laparoscopic surgery in elderly patients with colorectal cancer. Mol Clin Oncol 3: 897-901, 2015.

19. Baré M, Montón C, Mora L, Redondo M, Pont M, Escobar A, Sarasqueta C, Fernández de Larrea N, Briones E and Quntana JM: COPD is a clear risk factor for increased use of resources and adverse outcomes in patients undergoing intervention for colorectal cancer: A nationwide study in Spain. Int J Chron Obstruct Pulmon Dis 12: 1233-1241, 2017.

20. Nishikawa T, Ishihara S, Hata K, Murono K, Yasuda K, Otani K, Tanaka T, Kiyomatsu T, Kawai K, Nozawa H, et al: Short-term outcomes of open vs. laparoscopic surgery in elderly patients with colorectal cancer. Surg Endsc 30: 5550-5557, 2016.

21. Hinoi T, Kawaguchi Y, Hattori M, Okajima M, Ohdan $\mathrm{H}$, Yamamoto S, Hasegawa H,Horie H, Murata K, Yamaguchi S, et al: Laparoscopic versus open surgery for colorectal cancer in elderly patients: A multicenter matched case-control study. Ann Surg Oncol 22: 2040-2050, 2015.

22. Robinson CN, Balentine CJ, Marshall CL, Wilks JA, Anaya D, Artinyan A, Berger DH and Albo D: Minimally invasive surgery improves short-term outcomes in elderly colorectal cancer patients. J Surg Res 166: 182-188, 2011. 
23. Shigeta K, Baba H, Yamafuji K, Asami A, Takeshima K, Nagasaki K, Okamoto N, Murata T, Arai S, Kubochi K and Kitagawa Y: Effects of laparoscopic surgery on the patterns of death in elderly colorectal cancer patients: Competing risk analysis compared with open surgery. Surg Today 46: 422-429, 2016.

24. Gillou PJ, Quirke P, Thorpe H, Walker J, Jane DG, Smith AM, Heath RM and Brown JM; MRC CLASICC trial group: Short-term endpoints of conventional versus laparoscopic-assisted surgery in patients with colorectal cancer (MRC CLASICC trial): Multicentre, randomized controlled traial. Lancet 365: 1718-1726, 2005.

25. Lujan J, Valero G, Hernandez Q, Sanchez A, Frutos MD and Parrilla P: Randomized clinical trial comparing loparoscopic and open surgery in patients with rectal cancer. Br J Surg 96 : 982-989, 2009

26. van der Pas MH, Haglind E, Cuesta MA, Fürst A, Lacy AM, Hop WC and Bonjer HJ; COlorectal cancer Laparoscopic or Open Resection II (COLOR II) Study Group: Laparoscopic versus open surgery for rectal cancer (COLOR II): Short-term outcomes of a randomised, phase 3 trial. Lancet Oncol 14: 210-218, 2013.

27. Fleshman J, Branda M, Sargent DJ, Boller AM, George V, Abbas M, Peters WR Jr, Maun D, Chang G, Herline A, et al: Effect of laparoscopic-assisted resection vs. open resection of Stage II or III rectal cancer on pathologic outcomes. The ACOSOG Z6051 randomized clinical trial. JAMA 314: 1346-1355, 2015.
28. Stevenson AR, Solomon MJ,Lumley JW, Hewett P, Clouston AD, Gebski VJ, Davies L, Wilsn K, Hague W and Simes J; ALaCaRT Investigators: Effect of laparoscopic-assisted resection vs. open resection on pathological outcomes in rectal cancer. The ALaCaRT randomized clinical trial. JAMA 314: 1356-1363, 2015.

29. Kim MJ, Kim YS, Park SC, Sohn DK, Kim DY, Chang HJ and Oh JH: Risk factors for permanent stoma after rectal cancer surgery with temporary ileostomy. Surgery 159: 721-727, 2016.

30. Hassan I, Larson DW, Wolff BG, Cima RR, Chua HK, Hahnloser D, O'Byrne MM, Larson DR and Pemberton JH: Impact of pelvic radiotherapy on morbidity and durability of sphincter preservation after coloanal anastomosis for rectal cancers. Dis Colon Rectum 51: 32-37, 2008.

31. Lindgren R, Hallböök O, Rutegård J, Sjödahl R and Matthiessen P: What is the risk for a permanent stoma after low anterior resection of the rectum for cancer? A six-year follow-up of a multicenter trial. Dis Colon Rectum 54: 41-47, 2011.

32. Abe S, Kawai K, Nozawa H, Hata K, Kiyomatsu T, Tanaka T, Nishikawa T, Otani K, Sasaki K, Kaneko M, et al: Use of a nomogram to predict the closure rate of diverting ileostomy after low anterior resection: A retrospective cohort study. Int J Surg 47: 83-88, 2017. 